\begin{tabular}{|l|l|}
\hline $\begin{array}{l}\text { ESCOLA DE COMUNICAÇÃO, } \\
\text { ARTES E DESIGN } \\
\text { FUCRS }\end{array}$ & $\begin{array}{l}\text { FAMECOS } \\
\text { mídia, cultura e tecnologia } \\
\text { Revista FAMECOS, Porto Alegre, v. 27, p. 1-13, jan.-dez. } 2020 \\
\text { e-ISSN: 1980-3729 | ISSN-L: 1415-0549 }\end{array}$ \\
\hline https://dx.doi.org/10.15448/1980-3729.2020.1.35881
\end{tabular}

PENSAMENTO MIDIÁTICO COMUNICACIONAL

\title{
O que é circulação na comunicação? Dimensões epistemológicas
}

\author{
What is circulation in communication theory? Epistemological approaches \\ Qué es la circulación en la comunicación? Dimensiones epistemológicas
}

\author{
Rafael Grohmann ${ }^{1}$ \\ 0000-0003-1063-8668 \\ rafael-ng@uol.com.br
}

Recebido em: 2 out. 2019.

Aprovado em: 26 abr. 2020.

Publicado em: 17 set. 2020.

\section{(c) (1)}

Artigo está licenciado sob forma de uma licença Creative Commons Atribuição 4.0 Internacional.
Resumo: O artigo apresenta a perspectiva da circulação como um lugar epistemológico de onde se olha a comunicação, encarada como articulação de saberes. A partir da teorização sobre como apreender a circulação em perspectiva comunicacional, o texto debate três dimensões distintas e complementares da circulação como possibilidades para as teorias da comunicação: a) perspectiva semiodiscursiva, envolvendo análise do discurso e semiótica; b) estudos culturais; c) circulação comunicacional do capital, sendo essa entendida como um ponto-cego na área. Na articulação entre "circulação de sentidos" e "circulação do capital", apresentam-se potências teórico-metodológicas para o conceito no campo da comunicação, envolvendo lutas por circulação e disputas de sentidos. Palavras-chave: Circulação. Comunicação. Epistemologia.

Abstract: The article aims to analyze circulation as an epistemological place to communication research, as the articulation of knowledge. From the theorizing about how to understand circulation in a communicational perspective, the paper discusses three distinct and complementary dimensions of circulation as possibilities for communication theory: a) semiodiscursive perspective, involving discourse analysis and semiotics; b) cultural studies; c) communicational circulation of capital, which is understood as a blindspot in the area. In the articulation between "circulation of meanings" and "circulation of capital", theoretical and methodological potentialities for the concept in the field of communication are presented, involving struggles for circulation and disputes of meanings.

Keywords: Circulation. Communication. Epistemology.

Resumen: El artículo presenta la perspectiva de la circulación como un lugar epistemológico desde el cual mirar la comunicación, vista como una articulación de saberes. Desde la teorización sobre cómo aprehender la circulación en una perspectiva comunicacional, el texto discute tres dimensiones distintas y complementarias de la circulación como posibilidades para las teorias de la comunicación: a) perspectiva semi-discursiva, que involucra análisis del discurso y semiótica; b) estudios culturales; c) circulación comunicacional del capital, que se entiende como un punto ciego en el área. En la articulación entre "circulación de significados" y "circulación de capital", se presentan potencialidades teóricas y metodológicas para el concepto en el campo de la comunicación, que implican luchas por la circulación y disputas de significados.

Palabras clave: Circulación. Comunicación. Epistemologia.

\section{Introdução}

Os conceitos de onde se pode observar a comunicação são muitos e povoam os debates epistemológicos da área. A depender do radical chic da época, alguma palavra se sobressai em relação às outras. A noção de circulação é um operador central para pensar a comunicação, em 
seus aspectos teóricos e epistemológicos. Um conceito sobre o qual se fala, mas nem sempre se problematiza. Quais seriam algumas balizas ou dimensões para compreensão da circulação no âmbito da comunicação? Como apreender a circulação em uma visada comunicacional?

Em texto anterior (LELO; GROHMANN, 2014), discutimos algumas visões sobre a circulação². Uma das questões é que nem sempre a circulação aparece em primeiro plano nessas pesquisas, sendo às vezes um cenário para pensar questões discursivas mais amplas ou a questão da midiatização. A circulação tem "sondado" o campo, mas sem um enfrentamento efetivo para o debate de teorias e epistemologias da comunicação. Como algo visivel, tratado, mas não aprofundado, e muitas vezes naturalizado. A circulação circunda o campo, mas como coadjuvante de luxo. É, então, dificil apreender a circulação sem que seja uma metáfora: "tal assunto circulou na midia".

O artigo tem por objetivo teorizar sobre a circulação a partir de uma perspectiva comunicacional, buscando pensar esta noção como um lugar epistemológico de onde se olham os processos comunicacionais. $O$ estudo aqui apresentando refere-se às articulações do conceito enquanto teorias da comunicação e temáticas apropriadas pelo campo, independentemente de suas próprias origens - que podem vir de distintas áreas. Consideramos a comunicação epistemologicamente como um lugar de articulação e encontro de saberes, sendo a partir dessa multiplicidade que se olha a circulação.

A partir disso, o texto apresenta abordagens possiveis para apreensão do conceito no campo, a saber: perspectivas semiodiscursivas, envolvendo semiótica e análise do discurso; os estudos culturais; e a circulação comunicacional do capital, ancorada principalmente pela crítica da economia política. A escolha dessas abordagens não encerra todas as possiveis perspectivas no campo - como um olhar mais próximo ao interacionismo simbólico ou das materialidades midiáticas, por exemplo, e justifica-se, no caso das duas primeiras abordagens, pela sua relativa presença no campo enquanto teorias da comunicação, enquanto a terceira - especificamente em relação ao papel da comunicação na circulação do capital - tem se mostrado um ponto cego. $\mathrm{Na}$ articulação entre "circulação de sentidos" e "circulação do capital", há potencialidades teórico-metodológicas para a noção de circulação na pesquisa em comunicação.

\section{Teorizando sobre circulação}

Defendemos aqui a perspectiva da circulação como um lócus epistemológico de onde se olha a comunicação. Não se trata de repetir um modelo funcionalista linear de comunicação (SODRÉ, 2014), mas de compreendê-la em sua faceta circular - com deslocamentos, arestas, rupturas, continuidades e conflitos. Por isso, tratamos de entender a circulação mais como um olhar para a comunicação e seus processos do que como um conceito fechado e univoco.

A questão da circulação pode ser compreendida a partir da circulação de pessoas, espaços (HARVEY, 2018) e mercadorias (MARX, 2014), por exemplo. Isso nos interessa à medida em que revelam suas facetas comunicacionais. $O$ que nos une no campo da comunicação é menos a definição de um objeto em comum, mas a busca por "perspectivas" comunicacionais (FRANÇA, 2001). Isso porque a comunicação é uma ciência do encontro e da articulação - pontos de contatos que nos deixam entrever os processos comunicacionais. Essa perspectiva comunicacional, de onde falamos, é, pois, antes de tudo, um lugar de articulação de saberes. Com isso, não se trata de descartar, a priori, circulação de espaços ou mercadorias, mas de compreender suas dimensões comunicacionais, assim como outras possiveis dimensões da circulação.

Entendida em perspectiva não essencializante, a circulação a partir de um olhar comunicacional também nos mostra os seus limites. Nada (nem ninguém) circula indefinidamente, pois há materialidades, limites e contradições na vida social e comunicativa. Os próprios meios e suas infraestruturas

\footnotetext{
2 A saber: a semiolinguistica de Charaudeau, pesquisas britânicas que, ora enfocam em questões institucionais, ora em perspectivas interacionais, e os trabalhos dos brasileiros Fausto Neto e Braga.
} 
possibilitam determinadas maneiras de circulação em detrimento de outras e podem sugerir - eles mesmos - formas de circular a comunicação.

Isso significa dizer que pensar a circulação também envolve a "não circulação". Os debates sobre imigração, por exemplo, envolvem tanto a circulação quanto as tentativas de limitar a circulação de pessoas pelas cidades. Podemos pensar também a não circulação de mercadorias (greve de caminhoneiros, por exemplo), dados (a proibição de abertura e transparências de dados, por exemplo), discursos - midiáticos ou não - como interditos e silêncios.

Com isso, podemos dizer que há lutas por circulação nos processos comunicacionais. Embates e disputas pelos modos de circulação, como uma circulação tensa. Essa visão de "lutas por circulação" nos auxilia a não cair em uma visão de comunicação somente como consenso, mas de disputas de sentido perpassadas - e circuladas - nos processos comunicacionais.

Isso significa compreender os contextos da circulação, como temporalidades e espacialidades envolvendo os meios como infraestruturas de conexão (COULDRY, 2019). No caso de plataformas digitais, isso envolve gramaticalidades e lógicas algoritmicas, com normas e valores das plataformas inscritos nos rastros da circulação. Esses contextos também são marcados por dimensões sociais envolvidas nos processos comunicacionais.

A partir disso, falamos em "circulação comunicacional". Isso significa dizer que não restringimos à "circulação midiática" nem à "circulação jornalística". Um dos poucos autores brasileiros a enfatizar a dimensão comunicacional da circulação é Braga (2006), com seu "sistema de circulação interacional". Para ele, "a rigor, não é 'o produto' que circula - mas encontra um sistema de circulação no qual se viabiliza e ao qual alimenta" (BRAGA, 2012, p. 41). Assim, há um sistema de circulação envolvendo as interações, em que a comunicação é "um fluxo incessante de ideias, informações, injunções e expectativas que circulam em formas e reconfigurações sucessivas (BRAGA, 2012, p. 46).

Podemos perceber que Braga traz para a questão da circulação uma dimensão comunicacional, mas a) a questão da circulação aparece mais com um pano de fundo para o autor discutir interação e midiatização do que propriamente uma teorização acerca da circulação; b) em suas discussões, a comunicação acaba presa a um "microcosmo interacional", sem uma relação ao macrossocial.

Quando falamos em "circulação comunicacional", a ênfase (o que não significa nem determinação nem totalidade) recai sobre os "sentidos" - sejam eles discursivos, culturais ou do capital - circulados nos processos e relações de comunicação, midiatizados ou não. Essa circulação apresenta marcas, rastros e vestígios a partir de dimensões espaciais, temporais e seus contextos sociais, inclusive ideológicos. Os contextos da circulação ajudam a desenhar lutas e embates em torno da circulação comunicacional, entre circulação e não circulação (impedimentos e interditos). São lutas por sentidos em circulação - produzidos, consumidos, "ressemantizados" e cristalizados.

Podemos perceber, em linhas gerais, três dimensões ou abordagens para apreender a circulação em uma perspectiva comunicacional: semiodiscursivas, culturalistas e a que aqui chamamos de "circulação comunicacional do capital" - articulando a comunicação como produção de sentido à dimensão do modo de produção capitalista, com auxilio da economia política da comunicação, sem, no entanto, reduzir a comunicação a essas abordagens. Dentre essas três visadas, a última tem sido um ponto cego nos estudos de comunicação.

Essas dimensões devem ser entendidas como eixos que se se complementam, não como entes isolados. A articulação - entendida no sentido de Hall (2003) - entre essas perspectivas tem por objetivo procurar apreender a circulação em uma chave dialética no posicionamento dos objetos empíricos, sem perder nem a especificidade do micro - cotidiano, interacional - nem o contexto macrossocial dos sujeitos sociais.

\section{A circulação em dimensão semiodiscursiva}

Uma das maneiras possiveis de apreender, de uma perspectiva comunicacional, a circulação é a partir de uma dimensão que aqui denominamos 
como "semiodiscursiva", isto é, que pode envolver abordagens semiológicas, semióticas, linguisticas e discursivas. No âmbito da análise de discurso desenvolvida na França, Pêcheux (1981) deixa entrever a importância da circulação discursiva: "não é hora de descartar essa imagem duplamente complacente da circulação, observando o fato de que as circulações discursivas nunca são aleatórias, porque 'qualquer coisa' nunca é 'qualquer coisa'?" (PÊCHEUX, 1981, p. 18). Isto é, os discursos circulam de alguns modos e não de outros, a depender, por exemplo, de suas materialidades discursivas.

Na obra de Foucault (1996; 2009), o termo "circulação" aparece com frequência, mas de forma não sistemática - isto é, não como conceito trabalhado metodologicamente - e apresenta os seguintes sentidos: a) circulação dos efeitos de poder; b) circulação e funcionamento dos enunciados (ou a circulação de discursos que funcionam como "verdade"); c) o controle/fechamento da circulação dos discursos. A circulação, pois, aparece como uma noção coadjuvante, como afirmamos acima, como um apoio - quase invisivel - à concepção discursiva foucaultiana. As condições de produção dos discursos deixam entrever seus modos de circulação e o controle/ fechamento discursivo dessa circulação.

A noção, contudo, não ganhou centralidade na análise do discurso, principalmente nas últimas décadas. Como um exemplo, no Dicionário de análise do discurso, organizado por Charaudeau e Maingueneau (2004), não há nenhum verbete que se remeta à questão da circulação. Além disso, em Charaudeau (2006), há a definição de "discurso circulante", mas que diz mais sobre discurso do que efetivamente sobre circulação, sendo um elemento menor em um aparato conceitual que privilegia a questão do contrato de comunicação.

Atualmente, no cenário francófono, Rosier (2003) tem sido a autora a trabalhar de forma mais sistemática a noção de "circulação discursiva" a partir de uma perspectiva pecheutiana. Segundo ela, tratar de circulação significa mostrar como as palavras viajam, sua origem enunciativa e suas condições de "transmissão" (ROSIER, 2003). A autora diferencia a noção de circulação de inter- discursividade ou dialogismo, mas inscreve sua acepção a partir de suas materialidades discursivas, considerando que os discursos se movem temporal e espacialmente a partir de suportes materiais (PAVEAU; ROSIER, 2010).

Neste sentido, Rosier (2003) considera que o estudo da circulação "supõe a multiplicação da relação entre os espaços enunciativos: para ser um discurso em circulação, ele deve ter sido objeto de várias transmissões" (ROSIER, 2003, p. 51). Isso significa pesquisar a origem e os modos e métodos de disseminação dos discursos. A autora, então, concebe a fofoca como um exemplo típico da circulação discursiva: "sob o disfarce de um segredo aberto, ela só existe (re)colocada em circulação" (ROSIER, 2003, p. 51).

Em Rosier e outros. (2009), há a proposição de uma agenda para a questão da circulação dos discursos, no sentido de pesquisar: a) formas e modalidades da propagação dos discursos, incluindo os locais de difusão; b) posições ideológicas e lugares de enunciação; c) como ocorre a legitimidade e a autoridade dos discursos circulantes; d) apagamentos e remarcações enunciativas a partir das condições de circulação - isto é, modos de apagar ou reforçar discursos em sua circulação. Também faz parte desta agenda compreender as circunstâncias sociais e históricas da circulação discursiva, a cena discursiva e os seus dispositivos comunicacionais.

Ou seja, há uma proposta metodológica em Rosier e outros (2009) no sentido de como mapear a circulação dos discursos e seus contextos: a) onde circula, envolvendo suas próprias materialidades - plataformas, materiais impressos - e incluindo os gêneros discursivos; b) o que circula, quais valores são produzidos e circulados, envolvendo as posições ideológicas e os lugares de enunciação; c) quais as relações de poder envolvidas na circulação; d) o que há de silenciamentos, interditos e reforços, enquanto regimes de visibilidade da circulação discursiva. Os discursos - como lugar de materialização e sedimentação dos sentidos - dão-se a ver na circulação.

Outra proposição semiodiscursiva sobre a circulação é a de Eliseo Verón, explicitada prin- 
cipalmente na obra Semiotique Ouverte, escrito em coautoria com Jean-Jacques Boutaud (2007), onde falam acerca da "circulação dos discursos no seio das sociedades" (VERÓN; BOUTAUD, 2007, p. 18). O argumento central está na crítica do modelo funcionalista e linear de comunicação, buscando teorizar acerca da circulação discursiva a partir das relações entre gramáticas de produção e gramáticas de reconhecimento, que envolvem uma pluralidade de lógicas, sendo a circulação uma das fontes da complexidade social. Conforme o autor, em obra anterior, "circulação é o nome de um conjunto de mecanismos que formam parte do sistema produtivo, que definem as relações entre gramáticas de produção e gramáticas de reconhecimento para um discurso ou tipos de discursos dados" (VERÓN, 1996, p. 20). A circulação em Verón, desta forma, é encarada a partir dos deslocamentos e impermanências.

No Brasil, Fausto Neto (2010) segue os passos de Verón, considerando o trabalho de circulação como o lugar onde produtores e receptores se articulam em novas condições, considerando os deslocamentos e assimetrias que se dão nesse processo. Fausto Neto propõe abordar tanto as bordas ou vestígios da circulação quanto a circulação além de suas bordas. Trata-se, em sua visão, de analisar novas formas de organização de circulação dos discursos, passando da noção de "intervalo" para "pontos de contato". A complexificação dessa ideia de circulação, na visão do autor, está "condicionada a uma ação tecnodiscursiva desferida pela instância produtiva" (FAUSTO NETO, 2010, p. 7), isto é, se relaciona às mudanças nos regimes sociotécnicos.

A partir dos deslocamentos e das assimetrias provocadas pela circulação em contextos de midiatização, há lutas por controles de sentido. Isto é, os grandes meios perdem o controle das narrativas e dos sentidos dos acontecimentos. Essa premissa é analisada empiricamente em trabalhos subsequentes do autor, desde comentários sobre a saída de Fátima Bernardes do Jornal Nacional (FAUSTO NETO; SGORLA, 2013) até a circulação da campanha "Que Brasil você quer para o futuro?", mostrando a complexidade dos "feixes de sentidos": "calendários de outras lógicas são constituidos por temporalidades que se enunciam em marcas, cadências, cenários e desejos" (FAUSTO NETO, 2018, p. 11). Isso se assemelha ao que chamamos de "lutas por circulação". O reconhecimento das assimetrias e das disputas pelo controle dos feixes de sentido são centrais para o trabalho de circulação.

Para avançar, poderíamos perguntar: o que significam esses deslocamentos? Quais outras "lutas por circulação" ocorrem na circulação discursiva nas distintas plataformas midiáticas - não só de empresas midiáticas tradicionais? Como esses feixes de sentido passam também por controle algorítmico das plataformas digitais? Trata-se de uma complexificação não somente de uma "sociedade em vias de midiatização", mas da "dataficação" (COULDRY; HEPP, 2016) dos processos comunicacionais - e que tem implicações para o desenho da circulação.

Há outros circuitos onde o trabalho de circulação acontece que não engendradas por processos midiáticos tradicionais. Só é possível compreender, por exemplo, a circulação de mensagens no WhatsApp se considerarmos os tensionamentos desses lugares de enunciação. Por quais lugares e materialidades ocorrem a circulação comunicacional e como ela se dá em contextos de plataformas digitais? Como a complexidade dessa circulação nos auxilia a compreender rastros de processos comunicacionais na sociedade brasileira?

Enfim, o que tanto a perspectiva mais alinhada à Pêcheux quanto à visão de Verón/Fausto Neto tem em comum é a constatação de que a circulação dos discursos não acontece no vazio. Os modos e contextos de circulação - envolvendo desde as materialidades discursivas até questões ideológicas - com seus regimes de visibilidade deixam entrever tanto os distintos feixes de sentido em determinadas situações comunicacionais quanto as lutas por circulação - por controle dos sentidos. A perspectiva de Verón e Fausto Neto, por outro lado, avançam ao pensar a circulação de sentidos em contexto de midiatização.

São signos que circulam com determinados acentos e valores e não outros: em certa medida, 
uma arena para as lutas de classes, conforme preconizava Volochinov (2017), lutas essas inscritas nos processos comunicacionais. Deslocamentos, embates, rupturas, tensões, conflitos, reatualizações, reconhecimento de legitimidades e autoridade: algo marcado sempre por mudanças e permanências. Um lugar de onde se possa compreender as relações de poder marcadas nos processos comunicacionais: a circulação como lugar de embates. Embates situados no movimento histórico, que não se encontram no "início" ou no "fim", mas em movimento, como um "dando-se" (BACCEGA, 1995), um gancho que pegamos no "meio do caminho" - um modo de apreender metodologicamente um objeto empírico - mas que está envolto por fios de sentido, como novelos e redes tecidos nos processos comunicacionais.

Considerando, pois, que os discursos não se constituem no vazio, mas em processos históricos e culturais, a localização de seus rastros e vestígios de sentido na circulação comunicacional não são totalizados somente em uma dimensão semiodiscursiva, mas carecem de uma abordagem também cultural, sendo eixos complementares de análise.

\section{A circulação nos Estudos Culturais}

A questão da circulação de sentidos também aparece em uma abordagem culturalista. Para Lee e LiPuma (2002), mais do que movimentos de pessoas, mercadorias ou ideias, deve-se pensar em "culturas de circulação", o que também envolve a circulação de valor no capitalismo e os modos de circulação fora dos processos capitalistas, como a circulação do comum. Isso significa dizer que a circulação, em sua perspectiva comunicacional, também depende dessas culturas de circulação, ou seja, maneiras de produzir e consumir ideias, mercadorias e espaços, inclusive com determinados rituais, não somente midiáticos ou de consumo, mas de circulação, isto é, fazer circular determinadas formas culturais, produzindo e/ou modificando vínculos de sentido entre sujeitos e instituições.

Na história da pesquisa em comunicação, em uma abordagem a partir dos estudos culturais, há destaque para o "circuito de cultura" e uma perspectiva integrada produção-consumo para compreensão da circulação, por exemplo, Johnson (1999), Hall (2003) e DuGay, Hall et al. (1997), traçando paralelos entre circuito do capital e circuito de cultura: "o circuito é, a um só tempo, um circuito de capital (e sua reprodução ampliada) e um circuito de produção e circulação de formas subjetivas" (JOHNSON, 1999, p. 35). Essa perspectiva integrada coloca produção, circulação e consumo como parte do mesmo processo, mas com momentos diferentes e lógicas distintas, mas interligadas - à semelhança de Marx (2011) nos Grundrisse. ${ }^{3}$

As homologias entre circuito do capital e circuito da cultura, identificadas por Hall (2003) e Johnson (1999), servem-nos para mostrar que há dialética entre as diferentes dimensões dos processos de circulação comunicacional, ou seja, não é possivel uma leitura reducionista e mecanicista da cultura ou da economia, como se uma ou outra fossem apartadas da vida social material (WILLIAMS, 1979). Falar de circulação comunicacional a partir da cultura, portanto, é considerar essas dimensões como parte de processos homólogos e parte da vida concreta dos sujeitos.

Johnson (1999), ao pensar a circulação dos produtos culturais, reflete sobre as condições especificamente capitalistas de produção e consumo e deve ser desenhado em sua totalidade, embora, estrategicamente, possa escolher um recorte como apreensão metodológica. Em obra posterior, Johnson e outros (2004) consideram que localizar o "momento" dessa circulação é mais importante do que uma pretensa "quantidade" de dados e momentos: "o que importa é onde entramos em circuitos culturais" (JOHNSON et al., 2004, p. 177).

Hall (2003) apresenta um maior desenvolvimento teórico do circuito da cultura, também partindo da totalidade do circuito produção-consumo, isto é, o "entendimento do circuito do

3 Mais do que falar em circulação, Marx (2011) estava tratando, no contexto das mercadorias, do circuito produção-consumo, com suas mediações - em sentido lato - e identidades. A distribuição ou circulação de mercadorias faz parte desse mesmo circuito, envolto em mudanças tanto na produção quanto no consumo. 
capital como uma articulação dos momentos de produção com os momentos do consumo, com os momentos de realização, com os momentos de reprodução" (HALL, 2003, p. 356). O circuito do capital e o circuito da cultura devem ser vistos, nesta direção, como "articulações", onde a circulação de sentidos se faz e refaz. É nesse circuito de sentidos onde os significados podem ser estabelecidos e contestados, sedimentados e ressignificados, com tentativas de controle dos modos de significar o mundo - o que aqui chamamos de "lutas por circulação".

No famoso texto "Codificação/Decodificação", o que Hall (2003) enfatiza é que esses dois "momentos" são estruturas de sentido, da mesma forma que circulação e recepção são "momentos" do processo produtivo. A ideia de "momento", já presente em Marx (2011), sinaliza o desenho de um movimento, de como os sentidos se movem. Os sentidos sobre o que é ser pobre, rico, normal, migrante ou saudável, por exemplo, circulam entre os distintos momentos, com atualizações, fixações e tensões, com duplo deslocamento entre produção e consumo. Não como algo fechado ou contínuo, mas em permanentes articulações, desarticulações, rearticulações e ruidos, pois não existe processo comunicacional transparente.

Os processos de produção e consumo, sejam eles midiáticos, midiatizados, digitais, então, se atualizam na circulação a partir da apreensão dos sentidos. Conforme DuGay, Hall et al. (1997, p. 10), "os sentidos nos ajudam a interpretar o mundo [...], 'dar sentido' às coisas, incluindo aquelas que nunca vimos ou experienciamos na vida real, mas que ocorre em filmes e romances, sonhos e fantasias". Assim, trata-se de pensar como os sentidos são construidos por meio de práticas culturais e podem ser compartilhados, isto é, circulados em variados processos e práticas. Algumas perguntam levantadas por DuGay, Hall et al. (1997) vão na mesma direção de nosso argumento: "quais outros contra sentidos estão circulando? Quais sentidos são contestados? Como a luta entre diferentes conjuntos de significados reflete o jogo de poder e resistência ao poder na sociedade?" (DUGAY, HALL et al., 1997, p. 12).
Desde a década de 1990, houve atualizações e apropriações do circuito de cultura. Na introdução à segunda edição de Doing Cultural Studies, DuGay e Madsen (2013) acrescentam três temas ao circuito: a) as fronteiras entre público e privado como base para a regulação; b) as interrelações entre produção, consumo e identidade; c) a questão da representação nas midias digitais. Entre as apropriações da questão, estão o circuito/a circulação dos protestos em Cammaerts (2018) e o circuito de trabalho em Qiu, Gregg e Crawford (2014).

O circuito de cultura, a nosso ver, deve ser entendido menos como um protocolo metodológico, como se fosse uma apropriação funcional-estruturalista para operacionalização do circuito, do que um lugar também de articulação teórico-epistemológica, envolvendo o diálogo entre diferentes pontos de vista, como economia política, estudos culturais e estudos da linguagem. Isto é, um complexo que serve tanto para pensar a circulação da cultura e da comunicação nas pesquisas empíricas quanto para problematizar a própria circulação de saberes e, portanto, de métodos (SAVAGE, 2013), além da circulação de dados na cultura (BEER, 2016).

Outros pesquisadores britânicos, como Silverstone (2002) e Couldry (2000) vão além de um circuito definido previamente e enfatizam mais a circulação de sentidos. Silverstone (2002), por exemplo, compreende os processos comunicacionais como circulação de símbolos e significados, que são, a um só tempo, sociais e discursivos. Couldry (2000) chega a elaborar uma agenda de pesquisa para essa circulação de sentidos, envolvendo: "a) até que ponto os significados e associações são produzidos; b) quais textos são produzidos e como eles circulam; c) as várias maneiras pelas quais as pessoas usam ou negociam os vastos recursos textuais ao seu redor" (COULDRY, 2000, p. 83). Enquanto um "recurso", a circulação comunicacional depende tanto de negociação quanto de distribuição, o que está longe de ser uma busca habermasiana em torno de um consenso possivel, mas de disputas de poder em torno dos sentidos produzidos e circulados.

Então, na circulação, podemos observar como 
alguns sentidos são criados, fixados, reapropriados, desconstruidos ou ressignificados, revelando disputas e distinções no processo, como a circulação de lutas por sentido. Mas há barreiras de acesso a determinadas "arestas" da circulação, ou a determinados sentidos circulantes, já que não se trata de algo linear ou estanque, mas de algo incompleto, formado por articulações e tensões.

Em Grohmann (2019), tratamos de marcadores que atravessam a circulação de sentidos, desde classe, raça, gênero, geração e território dos sujeitos envolvidos. Aqui acrescentamos as próprias materialidades midiáticas (MURDOCK, 2018) - inclusive das plataformas digitais - cujos valores estão inscritos em suas arquiteturas. A circulação de sentidos é atravessada, pois, pelos desenhos dos meios, sem esquecer que as próprias tecnologias, como mostra Vieira Pinto (2005), são frutos do trabalho humano. Ou seja, a governança e as materialidades dos dispositivos midiáticos podem impor barreiras à circulação. No caso de plataformas digitais, há circuitos e circulações de ordenações algoritmicas, que possibilitam determinados regimes de visibilidades em detrimento de outros.

A partir dos marcadores enumerados acima, pensar em circulação comunicacional significa compreender como os significados e os sentidos são produzidos e reapropriados, mas também como as pessoas e mercadorias circulam, inclusive temporal e espacialmente. Trata-se de uma preponderância dos seres sociais e suas vidas cotidianas, práticas, materiais e concretas.

Livingstone (2018) afirma que a circulação de sentidos não deve ser compreendida "como a celebração do individualismo, mas do reconhecimento dos processos estruturalmente desiguais, embora semioticamente abertos, da circulação da cultura" (LIVINGSTONE, 2018, p. 5). Para uma abordagem que envolva a circulação de sentidos, não se trata de pensar metrificações, número de visualizações, indice verificador de comunicação (IVC), mas de compreender, muitas vezes, os "rastros" e "arestas" da circulação, a partir do contexto dos sujeitos sociais.

\section{Circulação comunicacional do capital}

Além das perspectivas semiodiscursivas e culturalistas, há outra possibilidade teórico-epistemológica da circulação na pesquisa em comunicação, mas que se apresenta como um ponto cego: a circulação comunicacional do capital. Os "sentidos" em circulação continuam a ter um papel relevante nesta dimensão, pois o próprio capital produz e sedimenta sentidos sobre o que deve ser a vida em sociedade, atualmente a partir de uma governamentalidade neoliberal (DARDOT; LAVAL, 2016), produzindo e fazendo circular sujeitos neoliberais. Há, então uma faceta discursivo-narrativa na circulação comunicacional do capital, além das materialidades do trabalho e a circulação da comunicação como mercadoria.

Para Marx (2011), os meios de transporte e de comunicação são essenciais para a circulação do capital, "no duplo de sentido de que determina tanto o circulo daqueles que trocam entre si, dos que entram em contato, como a velocidade com que a matéria-prima chega aos produtores e o produto, aos consumidores" (MARX, 2011, p. 134). É a partir do transporte e da comunicação que as mercadorias chegam aos sujeitos nos diferentes lugares, e se colocam como essenciais para "a concretização da produção material e da efetivação do mais-valor" (ANTUNES, 2018, p. 43).

Por quantos meios de transportes e seus trabalhadores passaram, por exemplo, os tomates desde sair da plantação até chegar em sua casa por meio de um entregador do aplicativo de delivery do supermercado? Sem a infraestrutura material, envolvendo força de trabalho e transportes, não há como pensar nas plataformas digitais, no modo de produção do capitalismo na própria comunicação. Isso demonstra mostra que a metáfora da nuvem (MOSCO, 2014) é somente uma pequena fração da produção e da circulação do capital, e não atua no vácuo, mas está envolvida nas materialidades do trabalho (MURDOCK, 2018). A própria circulação de sentidos, em termos semióticos, discursivos ou culturais, não pode se efetivar sem essas materialidades.

Além disso, como lembra Morley (2017), os transportes podem tanto conectar quanto dividir, 
considerando as desigualdades na ordem da mobilidade e das territorialidades. Nesse sentido, "questões de transporte e comunicação devem ser analisadas em termos de como 'redes' de infraestrutura de diferentes tipos permitem lou inibem) diferentes modos de atividade para diferentes setores da população" (MORLEY, 2017, p. 15). Assim, pode ocorrer tanto a circulação como a não circulação de pessoas e mercadorias, o que é também uma dimensão das lutas por circulação.

Já os meios de comunicação, por um lado, auxiliam na organização do transporte de mercadorias e de sua própria circulação. Marx (2013) nos lembra que a natureza das necessidades das mercadorias provém do estômago ou da imaginação. O papel da comunicação, enquanto parte do capital fixo constante (FUCHS, 2015), na organização da circulação de mercadorias, pois, também pode prover tanto do estômago quanto da imaginação ou fantasia. Assim, a comunicação age como organizadora dos modos de ser e narrar do capital, inclusive impondo modos e sentidos de circulação das mercadorias e do próprio capital.

No entrecruzamento do papel dos meios de transporte e comunicação na circulação das mercadorias, há pertinência para pensar o atual "capitalismo de plataforma" (SRNICEK, 2016) e a plataformização da sociedade (VAN DIJCK; POELL; DE WAAL, 2018) e do mundo do trabalho (GROHMANN, 2020). Aplicativos como Uber, iFood e Rappi funcionam a partir de plataformas digitais - tecnologias de comunicação - de onde extraem valor e reputação para as marcas, e com todo um circuito de meios de transporte, com trabalhadores atravessando as cidades, entregando mercadorias e transportando passageiros. Desta forma, há uma circulação comunicacional do trabalho nas plataformas digitais, onde podemos dizer que o "trabalho em plataformas" (VAN DOORN, 2017; GROHMANN; QIU, 2020) é um trabalho de circulação. A plataformização do trabalho, desta forma, só é possivel a partir da circulação - dos sentidos, das mercadorias e do capital.

A comunicação, ainda, contribui para a aceleração da circulação do capital, diminuindo o tempo de rotação, reduzindo o tempo morto e acelerando tanto a produção quanto o consumo. Conforme Harvey (2018), há um estímulo para uma constante espiral de aceleração do capital. Isto é, há uma aceleração em todo o circuito do capital que só é possivel com o papel da comunicação.

Essa circulação comunicacional do capital também apresenta seus próprios meios e processos de produção. Isso significa dizer que os meios de comunicação - como as próprias plataformas digitais - não só comunicam, mas também são meios de produção (WILLIAMS, 2011). Desta forma, uma plataforma não serve somente para se comunicar, mas é também um meio de produção. O Skype pode servir tanto para conversar com um familiar distante quanto para realizar reuniões e fazer cursos de idiomas com professor particular. Aplicativos de envio instantâneo de mensagens, como WhatsAppe Telegram, auxiliam tanto na troca de memes quanto na produção e circulação de material jornalístico.

As tecnologias são, ao mesmo tempo, de comunicação, de produção e de circulação. O seu potencial comunicativo é fartamente explorado na pesquisa em comunicação, mas há uma relativa ausência de sua imbricação com as dimensões da produção e da circulação, ao menos a partir do olhar aqui proposto. Não há como descolar a tecnologia do trabalho humano (VIEIRA PINTO, 2005). Só há valor, em sentido marxiano, nas tecnologias enquanto mercadorias, por causa da materialização (ou objetivação) do trabalho humano abstrato em sua produção. As tecnologias de circulação - assim como os próprios meios de comunicação - auxiliam a "encurtar o tempo de circulação do capital na produção e no mercado" (HARVEY, 2018, p. 99), ou seja, tem como função auxiliar a aceleração da própria circulação do capital, auxiliando, inclusive, na disseminação de dados. Isto é, há extração de riqueza principalmente na fase de distribuição. Uma questão que se coloca, então, é: como se produz valor a partir da circulação dos produtos culturais/midiáticos enquanto mercadorias por meio de plataformas digitais?

Para isso, é preciso pensar inter-relações entre financeirização, midiatização e dataficação assim como a circulação da própria linguagem. 
Fazem parte de dimensões discursivo-narrativas dessas tecnologias de circulação as perspectivas fetichizadas sobre inovações tecnológicas, atualmente expressas pela ideologia do Vale do Silício (SCHRADIE, 2017) e os mitos circulados em relação à gig economy (SCHOLZ, 2017), assim como a cultura de startups.

As noções de espaço e tempo também são primordiais para compreensão das tecnologias da circulação. Do ponto de vista do modo de produção capitalista, o intuito é de uma compressão espaçotemporal cada vez maior, com o capital ditando e redefinindo seus próprios tempos e espaços. As percepções de aceleração da vida cotidiana, em alguma medida, se relacionam com o espraiamento da lógica capitalista a todos os dominios da vida, o que Wendy Brown (2016) chama de disseminação da razão neoliberal. Wajcman (2019) mostra, em pesquisa com engenheiros e designers que trabalham e moram no Vale do Silicio, como a produção de calendários - um artefato que marca o tempo - digitais tem como um dos princípios a eficiência e otimização de tempo, com o "tempo sendo visto como um recurso individualista, uma mercadoria" (WAJCMAN, 2019, p. 14).

Desta maneira, o tempo de circulação das mercadorias e a aceleração da circulação do capital estão em linha com as dinâmicas temporais engendradas pela lógica capitalista em conexão com as tecnologias digitais. Os movimentos de circulação do capital, com destaque para a incessante aceleração, não se circunscrevem a uma ação somente econômica, mas são justificados e incorporados em todas as dimensões da vida, com um papel preponderante da comunicação. São os sentidos do capital em circulação e afetam, inclusive, as dimensões semiodiscursiva e culturalista.

A circulação desenfreada de conteúdos midiáticos e digitais (e também de dados), inclusive, é parte do que Jodi Dean (2008) chama de "capitalismo comunicativo" - não em uma acepção habermasiana, mas no sentido de que há uma política de circulação em detrimento dos próprios sentidos. Não consideramos que esses signos são destituídos de sentido, mas, ao contrário, que a própria circulação é o sentido que ajuda a mobilizar todos os outros, ou ainda, sem circulação incessante não há como produzir sentidos no "capitalismo comunicativo".

A circulação comunicacional do capital, pois, está envolvida na circulação de sentidos e na própria circulação de mercadorias, acelerando os fluxos do capital e da sociedade como um todo, modificando relações espaçotemporais. Ela apresenta uma faceta material, enquanto processo e meio de produção, envolvendo os circuitos e materialidades do trabalho, e também uma faceta discursivo-narrativa, com signos circulantes ou gramática circulante do capital.

A comunicação atua como articuladora dos sentidos do capital em circulação. Mobiliza discursos, processos produtivos e tecnologias espraiando para todos os lados da vida social a racionalidade neoliberal. A aceleração da circulação do capital é sintetizada no processo de financeirização-dataficação. Mas esse não é cenário cristalizado, assujeitado ou naturalizado. A força do capital pode ser quase totalizadora, mas não chega a ser total. Esse é o papel das lutas por circulação. Se há disputas de sentido, as lutas acontecem, mesmo que não seja em mesmo peso de igualdade. É preciso considerar como central, de acordo com Harvey (2018, p. 56), "as relações entre o valor que circula como capital e a construção e reconstrução perpétua dos valores políticos, culturais e estéticos". Que modos outros há de fazer circular a vida em sociedade? Como modificar chaves de sentido em um domínio quase completo da racionalidade neoliberal?

A circulação das lutas no âmbito da circulação comunicacional do capital envolve ainda as tentativas da circulação do comum (DE PEUTER; DYER-WITHEFORD, 2010; DARDOT; LAVAL, 2017) de brechas ou fissuras no modo de produção capitalista, enquanto circuitos de acumulação e resistência. Lutas em torno da circulação do capital que podem trazer tanto constrangimentos quanto brechas para ações em busca de outros mundos possiveis ou "utopias reais" (WRIGHT, 2010). São disputas e lutas, também, por sentidos. Desta forma, as lutas que se dão na circulação do capital envolvem não só as disputas internas, 
mas modos de fazer circular outras formas de vida. Entre circulação do capital e circulação do comum, está a comunicação. Ao mesmo tempo, articuladora dos modos de aparecer do capital e potência da vinculação dos seres sociais.

\section{Considerações finais}

Ao teorizarmos sobre circulação em perspectiva comunicacional, trouxemos facetas semiodiscursivas, culturalistas e a dimensão comunicacional da circulação do capital - todas como possibilidades para enfrentar o conceito no campo, sem fechá-lo ou cristalizá-lo. Essas três perspectivas trazem especificidades, como foram evidenciadas acima, mas a sua riqueza justamente está na articulação entre elas, pois não são maneiras excludentes de compreender a circulação e seus rastros na comunicação. Os acentos - na linguagem, na cultura e no capital - são apenas para efeitos didáticos, pois são elementos entrecruzados e constituintes dos processos comunicacionais.

Isto é, longe de uma visão dualista sobre a circulação comunicacional, como se fosse dividida entre circulação de sentidos e circulação do capital, o que há é uma imbricação e articulação dessas dimensões, pois a circulação de sentidos em um mundo capitalista está, em menor ou maior grau, envolvido com as suas questões, até para lutar por outras circulações. Enfim, a circulação discursiva, a circulação da cultura e a circulação do capital se encontram - em dimensões distintas - nos processos comunicacionais.

Reconhecer o papel da comunicação na circulação do capital - e seus múltiplos sentidos - é não somente para analisá-lo, como alguém que não fosse interferido por essas questões. repensar em perspectiva radical a teoria e pesquisa em comunicação em busca de formas de atuação na realidade material.

Isso demanda redesenhar o que comumente é chamado de epistemologia da comunicação, no sentido de não se fechar em uma "epistemologia pela epistemologia" ou em uma razão escolástica (BOURDIEU, 2001). Depois de, no mínimo, duas décadas de disputas sobre qual seria a perspectiva comunicacional mais legítima ou de definir, de antemão, os limites do próprio campo, excluindo o que seria, por hipótese, "não comunicacional", precisamos reconhecer-nos com as nossas impurezas e mestiçagens epistemológicas. Isso significa abrir os sentidos (epistemológicos) em circulação da própria comunicação e fazer circular suas pesquisas para outras áreas, não fechando em si mesma.

O campo concreto da ciência brasileira explodiu e exige respostas urgentes. Em contexto de plataformização da sociedade, é a comunicação uma das áreas que tem mais possibilidades de ser protagonistas dos debates mais importantes para a sociedade. É, então, a partir de um olhar mais generoso para a própria área que podemos - em articulação com outros saberes - exercer o que Vieira Pinto (1979) chama de "periculosidade social da ciência", pois, em sua visão, não é possivel existir ciência inocente "porque só seria tal aquela que não servisse para nada, o que seria a negação da sua essência. O conhecimento é sempre uma arma do homem na luta contra forças adversas, físicas ou sociais" (VIEIRA PINTO, 1979, p. 373).

Os sentidos epistemológicos de comunicação, em momento de financeirização-dataficação e quase-totalização de racionalidade neoliberal, são de colocar em disputa outras maneiras de circular o próprio campo de investigação para outras áreas do conhecimento. A comunicação é essencial à ciência hoje se atuar como articuladora entre os diferentes saberes, sem descartar a priori outras visões. Mostramos, em alguma medida, como o debate sobre circulação atravessa diferentes saberes. É a comunicação que os costura.

Definir algo como propriamente comunicacional pode ser um ponto de partida metodológico, mas nunca um ponto de chegada, pois isso fecharia os sentidos para a diversidade de possibilidades epistemológicas de fazer circular os saberes. Assim, descobrimos elementos empíricos e teóricos que vão além do que seria algo propriamente comunicacional, mas devem estar em nossas pesquisas. Desta forma, podemos compreender o campo da comunicação, como afirmamos desde o início, mais como um lugar de articulação - no sentido de Hall (2003) - de 
diferentes perspectivas. Nessa constante (re) articulação de saberes, a própria circulação da pesquisa em comunicação pode ampliar, inclusive pensando o papel da comunicação científica. A dimensão epistemológica da comunicação também é um lugar de lutas por sentido.

\section{Referências}

ANTUNES, Ricardo. O privilégio da servidão. São Paulo: Boitempo, 2018

BACCEGA, Maria Aparecida. Palavra e discurso. São Paulo: Ática, 1995.

BEER, David. Metric Power. Londres: Palgrave, 2016. https://doi.org/10.1057/978-1-137-55649-3.

BOURDIEU, Pierre. Meditações pascalianas. Rio de Janeiro: Bertrand Brasil, 2001.

BRAGA, José Luiz. A sociedade enfrenta sua mídia. São Paulo: Paulus, 2006.

BRAGA, José Luiz. Circuitos versus campos sociais. In: MATTOS, Maria Angela; JACKS, Nilda; JANOTTI Jr, Jeder. Mediação \& Midiatização. Salvador: UFBA, 2012. p. 31-52.

BROWN, Wendy. El pueblo sin atributos. Barcelona: Malpaso, 2016.

CAMMAERTS, Bart. The circulation of anti-austerity protest. London: Palgrave, 2018. https://doi. org/10.1007/978-3-319-70123-3.

CHARAUDEAU, Patrick. Discurso das Midias. São Paulo: Contexto, 2006.

CHARAUDEAU, Patrick; MAINGUENEAU, Dominique. Dicionário de análise do discurso. São Paulo: Contexto, 2004

COULDRY, Nick. Inside Culture. London: Sage, 2000 https://doi.org/10.4135/9781849209267.

COULDRY, Nick. Media: why it matters. Londres: Polity, 2019.

COULDRY, Nick; HEPP, Andreas. The mediated construction of reality. Londres: Polity Press, 2017.

DARDOT, Pierre; LAVAL, Christian. A nova razão do mundo. São Paulo: Boitempo, 2016.

DARDOT, Pierre; LAVAL, Christian. Comum. São Paulo: Boitempo, 2017.

DEAN, Jodi. Communicative Capitalism: circulation and the foreclosure of politics. In: BOLER, Megan (org.). Digital Media and Democracy. Londres: MIT Press, 2008. p. 101-122

DE PEUTER, Greig; DYER-WITHEFORD, Nick. Commons and cooperatives. Affinities: A Journal of Radical Theory, Culture, and Action, Kington (CA), v. 4, n. 1, p. 30-56, 2010.
DU GAY, Paul; HALL, Stuart et al. Doing Cultural Studies: the story of the Sony Walkman. Londres: The Open University/Sage, 1997.

DU GAY, Paul; MADSEN, Ander. Introduction to the second edition. In: DU GAY, Paul; HALL, Stuart et al. Doing Cultural Studies: the story of the Sony Walkman. 2. ${ }^{a}$ ed. London: Sage, 2013. p. [1-40].

FAUSTO NETO, Antônio. A circulação além das bordas In: FAUSTO NETO, Antonio; VALDETTARO, Sandra (org.). Mediatización, sociedad y sentido. Rosário: Departamento de Comunicación - UNR, 2010. p. 2-17

FAUSTO NETO, Antônio. Nos limites da mediação: "Que Brasil você quer para o futuro?", "Quero o Brasil do presente". In: $27^{\circ}$ Encontro Anual da Compós, 2018, Belo Horizonte. Anais [...]. Belo Horizonte: PUC-MG, 2018. v. 1. p. 1-12.

FAUSTO NETO, Antônio; SGORLA, Fabiane. A travessia de Fátima Bernardes: "estamos órfãos: o JN não tem mais sentido". In: OLIVEIRA, Ivone; MARCHIORI, Marlene (org,). Comunicação, discurso, organizações. São Caetano do Sul: Difusão Editora, 2013. p. 195-212.

FOUCAULT, Michel. A ordem do discurso. São Paulo: Loyola, 1996.

FOUCAULT, Michel. A arqueologia do saber. Rio de Janeiro: Forense Universitária, 2009.

FRANÇA, Vera. Paradigmas da comunicação: conhecer o quê? Ciberlegenda, [s. l.], n. 5. p. [1-19], 2001.

FUCHS, Christian. Reading Marx in the Information Age. Nova York: Routledge, 2015. https://doi. org/10.4324/9781315669564.

GROHMANN, Rafael. Os rastros digitais na circulação de sentidos: pela desnaturalização e contextualização de dados na pesquisa em comunicação. Galáxia, São Paulo, n. 42, p.150-163, 2019. https://doi.org/10.1590/198225532019340183

GROHMANN, Rafael. Plataformização do trabalho: entre dataficação, financeirização e racionalidade neoliberal. Revista Eptic. São Cristóvão, SE, v. 21, n. 1, p. 106-122, 2020.

GROHMANN, Rafael; QIU, Jack. Contextualizando o trabalho em plataformas. Contracampo: Brazilian Journal of Communication, Niterói, RJ, v. 39, n. 1, p. [1-10], 2020. https://doi.org/10.22409/contracampo.v39i1.42260.

HALL, Stuart. Da diáspora: identidades e mediações culturais. Belo Horizonte: UFMG, 2003.

HARVEY, David. A Loucura da razão econômica. São Paulo: Boitempo, 2018.

JOHNSON, Richard. O que é, afinal, estudos culturais? In: SILVA, Tomaz Tadeu da (org.) O que é, afinal, estudos culturais? Belo Horizonte: Autêntica, 1999.

JOHNSON, Richard et al. The Practice of Cultural Studies. Londres: Sage, 2004.

LEE, Benjamin; LiPUMA, Edward. Cultures of Circulation: the imaginations of modernity. Public Culture, Chicago, Ill., US, v. 14, n. 1, p. 191-213, 2002. https://doi. org/10.1215/08992363-14-1-191. 
LIVINGSTONE, Sonia. Audiences in a Age of Datafication: critical questions for media research. Television \& New Media. [s. l.], v. 20, n. 2, p. 170-183, 2018. https:// doi.org/10.1177/1527476418811118.

MARX, Karl. Grundrisse. São Paulo: Boitempo, 2011

MARX, Karl. O Capital: Livro I. São Paulo: Boitempo, 2013

MARX, Karl. O Capital: Livro II. São Paulo: Boitempo, 2014.

MORLEY, David. Comunicação e Transporte: a mobilidade de informação, de pessoas e de mercadorias. Eco-Pós, Rio de Janeiro, v. 20, n. 3, p. 10-38, 2017. https:// doi.org/10.29146/eco-pos.v20i3.14471.

MOSCO, Vincent. To the cloud. Londres: Routledge, 2014. https://doi.org/10.4324/9781315631554.

MURDOCK, Graham. Media Materialties: for a moral economy of machines. Journal of Communication, New York, US, v. 68, n. 2, p. 359-368, 2018. https://doi. org/10.1093/joc/jax023.

PAVEAU, Marie Anne; ROSIER, Laurence. Le discours des objets: pratiques et techniques de circulation. Cédille, [s. l.], v. 1, p. 178-196, 2010. https://doi. org/10.21071/ced.v1io.10553.

PÊCHEUX, Michel. Ouverture du colloque. In: CONEIN, Bernard e outros. Matérialités Discursives. Lille: Presses Universitaires de Lille, 1981.

QIU, Jack; GREGG, Melisa; CRAWFORD, Kate. Circuits of Labour: a labour theory of the iPhone era. Triplec, Is. l.], v. 12, n. 2, p. 564-581, 2014. https://doi.org/10.31269/ triplec.v12i2.540.

ROSIER, Laurence. Du discours rapport à la circulation des discours: l'example des dictionnaires de 'critique ironique'. Estudios de Lengua y Literatura francesas, Cadiz, ES, v. 14, p. 63-81, 2003.

ROSIER, Laurence e outros. La circulation des discours. Québec: Éditions Nota Bene, 2009.

SAVAGE, Mike. The 'Social Life of Methods': a critical introduction. Theory, Culture \& Society, London, v. 30, n. 4, p. 3-21, 2013. https://doi.org/10.1177/0263276413486160.

SCHOLZ, Trebor. Cooperativismo de plataforma. São Paulo: Rosa Luxemburgo, 2017.

SCHRADIE, Jen. Ideologia do Vale do Silício e desigualdades de classe. Parágrafo, São Paulo, v. 5, p. 85-99, 2017.

SILVERSTONE, Roger. Complicity and collusion in the mediation of everyday life. New Literary History, Baltimore, MD, v. 33, n. 5, p. 761-780, 2002. https://doi. org/10.1353/nlh.2002.0045.

SODRÉ, Muniz. A ciência do comum. Petrópolis: Vozes, 2014.

SRNICEK, Nick. Platform capitalism. Londres: Polity, 2016.

VAN DIJCK, José; POELL, Thomas; DE WAAL, Martijn. The platform society. Nova York: Oxford, 2018. https:// doi.org/10.1093/oso/9780190889760.001.0001.
VAN DOORN, Niels. Platform Labor: on the gendered and racialized exploitation of low-income service work in the 'on-demand' economy. Information, Communication \& Society, Is. l.], v. 20, n. 3, p. 898-914, 2017. https://doi.org/10.1080/1369118X.2017.1294194.

VERÓN, Eliseo. La Semiose Social. Barcelona: Gedisa 1996.

VERÓN, Eliseo; BOUTAUD, Jean-Jacques. La Semiotique Ouverte. Paris: Hermes Sciences, 2007.

VIEIRA PINTO, Álvaro. Ciência e existência. Rio de Janeiro: Paz e Terra, 1979.

VIEIRA PINTO, Álvaro. O conceito de tecnologia. Rio de Janeiro: Contraponto, 2005

VOLOCHINOV, Valentin. Marxismo e filosofia da Linguagem. São Paulo: Ed. 34, 2017.

WAJCMAN, Judy. How Silicon Valley Sets Time. New Media \& Society, [s. l.], v. 21, n. 6, p. 1272-1289, 2019. https://doi.org/10.1177/1461444818820073.

WILLIAMS, Raymond. Marxismo e literatura. Rio de Janeiro: Zahar, 1979

WILLIAMS, Raymond. Cultura e materialismo. São Paulo: Unesp, 2011.

WRIGHT, Erik Olin. Envisioning real utopias. Nova York: Penso, 2010.

\section{Rafael Grohmann}

Doutor em Ciências da Comunicação pela Universidade de São Paulo (USP), em São Paulo, SP, Brasil; professor do Programa de Pós-Graudação em Ciências da Comunicação, na Universidade do Vale do Rio dos Sinos (Unisinos), em São Leopoldo, RS, Brasil.

\section{Endereço para correspondência}

Rafael Grohmann

Universidade do Vale do Rio dos Sinos

Av. Unisinos, 950

Cristo Rei, 93022750

São Leopoldo, RS, Brasil 